\title{
Strategies for Communicating with Deaf Patients in the Public Physical Rehabilitation Unit in the Central South Region of Rio de Janeiro State, Brazil
}

\author{
Wiliam César Alves Machado', Juarez de Souza Pereira1, \\ Luciana Krauss Rezende ${ }^{3}$ \\ ${ }^{1}$ Federal University of the State of Rio de Janeiro, Rio de Janeiro, Brazil \\ ${ }^{2}$ Pontifical Catholic University of Rio de Janeiro, Rio de Janeiro, Brazil \\ ${ }^{3}$ Federal University of Itajubá, Itajubá, Brazil \\ Email: wilmachado@uol.com.br
} Nébia Maria Almeida de Figueiredo, Manoel Francisco de Souza Pereira ${ }^{2}$, Teresa Tonini1,

Received 23 January 2015; accepted 2 February 2015; published 5 February 2015

Copyright (C) 2015 by authors and Scientific Research Publishing Inc.

This work is licensed under the Creative Commons Attribution International License (CC BY). http://creativecommons.org/licenses/by/4.0/

\section{(c) (i) Open Access}

\section{Abstract}

Deaf people face communication difficulties in health units because of the lack of preparedness of health care professionals to deal with these patients. Objective: To identify how physical rehabilitation professionals associated with a regional public unit in the south central region of Rio de Janeiro State, Brazil interact with deaf patients. Method: Data were analyzed through descriptive statistics in the Statistical Package for Social Sciences (SPSS) software version 18. Results: Results showed that: $15.1 \%$ (5) of the team members did not know the Brazilian Sign Language (Libras) and required help in their interaction with deaf patients; $12.1 \%$ (4) never assisted deaf patients; $18.2 \%(6)$ used writing and gestures; $21.2 \%$ (7) resorted to lip-reading or gestures; $3.1 \%$ (1) spoke slowly; 6.1\% (2) used mime; 15.1\% (5) used the Brazilian Sign Language; $9.1 \%$ (3) did not respond. Conclusion: Most of these professionals are not prepared to satisfactorily interact with deaf patients. They use improvised strategies to assist the deaf clientele, demonstrating that the planning and implementation of regular courses in sign language are fundamental in order to assist these patients effectively.

\section{Keywords}

Deafness, Rehabilitation Unit, Sign Language

How to cite this paper: Machado, W.C.A., de Souza Pereira, J., de Figueiredo, N.M.A., de Souza Pereira, M.F., Tonini, T. and Rezende, L.K. (2015) Strategies for Communicating with Deaf Patients in the Public Physical Rehabilitation Unit in the Central South Region of Rio de Janeiro State, Brazil. Open Journal of Therapy and Rehabilitation, 3, 14-22. 


\section{Introduction}

Like any other user, deaf patients use public health services offered in many cities in Brazil. However, they do not receive appropriate assistance in physical rehabilitation units. Professionals working in these units should interact properly with each other to develop a joint rehabilitation program to meet the needs of this clientele [1]-[4]. Hence, what occurs in the majority of health units, in the public or private sector, is the lack of preparation, skills and willingness in professionals to embrace patients who differ from the norm, such as the deaf, without distinction.

In the clinical-therapeutics concept, deafness is still seen as a disease/deficit and as an impairment to be treated, corrected or cured. Thus, learning the oral language is one form used by deaf persons to compensate for the disability and improve chances to succeed in the society. Conversely, in the socio-anthropological conception, the term deaf refers to any person who cannot listen, regardless of the degree of hearing loss. Therefore, deafness is understood as different, a deaf person is perceived as different from listeners, and this difference results from how deaf people have access to the world through vision [5].

According to the manual entitled The Person with Disability and the Unified Health System published by the Ministry of Health, the integral health attention to people with disabilities presupposes specific assistance to their conditions, as well as the assistance to illnesses and diseases, common to any citizen. Thus, the scenario of this study stands out as a regional reference to support assistance to this clientele [6]. Therefore, it is assumed that professional teams are guided to fully include the disabled person. The communication with deaf patients is the object of this study [7].

A study on deaf people conducted in Fortaleza, Ceará, Brazil identifies that the blocked communication between deaf patients and health professionals is one of the major obstacles for the deaf community, when they seek health services. Deaf patients need to be assisted in a global way, having their beliefs, values and differences respected [8].

Census data from the Brazilian Institute of Geography and Statistics (IBGE) from 2010 showed that $23.9 \%$ $(45,623,910)$ of the resident population in the country $(190,755,799)$ presented at least one of the investigated disabilities: visual, auditory, motor, mental or intellectual. Thus, hearing impairment affects 9,722,163 people, among of which 347,481 have complete hearing loss, 1,799,885 have great difficulty to hear, and 7,574,797 have some hearing difficulty [9]. This information reveals the importance of knowledge of the Brazilian Sign Language by professionals working in health units to provide appropriate services to 9,722,163 Brazilian deaf individuals.

It is important to note that communication between health professionals and people with normal hearing is verbal, a mechanism not normally used by deaf people who use sign language to communicate. Screen language has a spatial-visual mode, because the shared signs are received by the eyes and its production is performed in space by hands. It is recognized as a language by Linguistic, which gives it the concept of a natural language and does not consider it as a problem of the deaf or as language pathology [10].

Because deaf people face communication difficulties in health units, the aim of this study is to identify how professionals who integrate the physical rehabilitation team in a regional public unit, in the South Central region of Rio de Janeiro State, Brazil interact with deaf patients. Knowledge of the Brazilian Sign Language is fundamental for planning the rehabilitation program for this clientele.

\section{Method}

This was exploratory research with a quantitative approach conducted in the first half of 2013. The study follows the provisions of resolution No. 466/2012 from the National Health Council/MS, which regulates the standards of research involving humans. The project was approved by the Research Ethics Committee from the Federal University of Rio de Janeiro State-UNIRIO under Protocol No. 289701 from 27 March 2013.

The study was performed at the physical rehabilitation unit belonging to the regional public sphere and duly registered in the National Council of Health Establishments (CNES), which provides service to users of the Unified Health System in the Central South region of the Rio de Janeiro State, located in the city of Três Rios, Rio de Janeiro State.

A total of 33 professionals who work in the screen rehabilitation unit team participated in this study. Because deaf patients must interact and be understood by all professionals working in the rehabilitation unit, which could 
ensure their complete inclusion when using the rehabilitation program, the study subjects were randomly selected among the professional categories after fitting into the study inclusion criteria.

The inclusion criteria were: being over 18 years old, professional team member of the physical rehabilitation staff from the regional public unit, called Planet Life, located in the Central-South region of Rio de Janeiro State, agreeing to voluntarily participate in the study, and signing a Volunteer and Informed Term of Consent.

Data were collected through a self-applied questionnaire, with a full transcript and subsequent statistical analysis. The questionnaire application was preceded by the presentation of the objectives of the study to participants and answers to possible questions regarding the questions in the instrument. Subsequently, the participants had sixty minutes to answer the questionnaire. The data was analyzed using the SPSS (Statistical Package for Social Sciences) software version 18, through descriptive statistics analysis, including sociodemographic profile data. The scores are presented by the sum in each group (n) and percentages (\%).

\section{Results}

Table 1 presents the sociodemographic characteristic of the participants distributed by age, gender, profession and professional performance time.

Table 1. Sociodemographic characteristics of participants, Três Rios/Rio de Janeiro State/RJ, 2013.

\begin{tabular}{|c|c|c|}
\hline Categories & $\mathbf{n} / \mathbf{3 3}$ & $\%$ \\
\hline \multicolumn{3}{|l|}{ Age } \\
\hline $21-30$ & 6 & 18.2 \\
\hline $31-40$ & 18 & 54.5 \\
\hline $41-50$ & 5 & 15.2 \\
\hline $51-60$ & 3 & 9.1 \\
\hline$>61$ & 1 & 3.0 \\
\hline \multicolumn{3}{|l|}{ Gender } \\
\hline Female & 24 & 72.7 \\
\hline Male & 9 & 27.3 \\
\hline \multicolumn{3}{|l|}{ Profession } \\
\hline Physical therapist & 9 & 27.3 \\
\hline Psychologist & 4 & 12.1 \\
\hline Nutritionist & 2 & 6.1 \\
\hline Nursing technician & 2 & 6.1 \\
\hline Nurse & 1 & 3.0 \\
\hline Receptionist & 3 & 9.1 \\
\hline Gym teacher & 2 & 6.1 \\
\hline Dentist & 2 & 6.1 \\
\hline Social worker & 1 & 3.0 \\
\hline Pedagogue & 1 & 3.0 \\
\hline Program coordinator & 1 & 3.0 \\
\hline Administrative assistant & 1 & 3.0 \\
\hline Phonoaudiologist & 2 & 6.1 \\
\hline Occupational therapist & 1 & 3.0 \\
\hline
\end{tabular}




\section{Continued}

Doorman

3.0

Time of professional performance

$\begin{array}{lcr}<1 \text { year } & 1 & 3.0 \\ 1-5 \text { years } & 11 & 33.3 \\ 6-10 \text { years } & 11 & 33.3 \\ 11-15 \text { years } & 2 & 6.1 \\ 16-20 \text { years } & 2 & 6.1 \\ 21-25 \text { years } & 4 & 12.1 \\ >30 \text { years } & 2 & 6.1\end{array}$

Most of the study participants are 31 - 40 years old female physiotherapy professionals with 1 - 10 years of experience. Participant age ranged between 21 and 61 years old, showing that the team consists of young and old professionals, and indicating broad possibilities of empathy and embracement of patients in rehabilitation programs, which is important due to the fact these patients undergo various barriers in an attempt to overcome functional losses.

When asked about what kind of strategy they use to communicate with the deaf clientele, the participants responded according to the data presented in Table 2.

Table 2. Communication strategies used by professionals with deaf patients, Três Rios/Rio de Janeiro State/RJ, 2013.

\begin{tabular}{|c|c|c|c|c|c|c|c|c|}
\hline Professionals & $\begin{array}{l}\text { I do not know } \\
\text { and I ask for } \\
\text { help }\end{array}$ & $\begin{array}{l}\text { Never } \\
\text { assisted } \\
\text { deaf } \\
\text { patients }\end{array}$ & $\begin{array}{l}\text { Through } \\
\text { writing and } \\
\text { gestures }\end{array}$ & $\begin{array}{l}\text { Lip reading } \\
\text { or } \\
\text { gestures }\end{array}$ & $\begin{array}{l}\text { Speaking } \\
\text { slowly }\end{array}$ & Mime & Libras & No response \\
\hline Recep. & 2 & 0 & 1 & 0 & 0 & 0 & 0 & 0 \\
\hline Soc. worker & 1 & 0 & 0 & 0 & 0 & 0 & 0 & 0 \\
\hline Coord. & 0 & 0 & 1 & 0 & 0 & 0 & 0 & 0 \\
\hline Dent. & 0 & 0 & 0 & 2 & 0 & 0 & 0 & 0 \\
\hline Nur. & 0 & 0 & 0 & 1 & 0 & 0 & 0 & 0 \\
\hline Phys. therap. & 2 & 1 & 0 & 1 & 1 & 1 & 0 & 3 \\
\hline Phono. & 0 & 0 & 0 & 0 & 0 & 0 & 2 & 0 \\
\hline Doorm. & 0 & 0 & 1 & 0 & 0 & 0 & 0 & 0 \\
\hline Nut. & 0 & 1 & 1 & 0 & 0 & 0 & 0 & 0 \\
\hline Gym teach. & 0 & 0 & 1 & 1 & 0 & 0 & 0 & 0 \\
\hline Pedag. & 0 & 0 & 0 & 0 & 0 & 0 & 1 & 0 \\
\hline Psych. & 0 & 2 & 0 & 0 & 0 & 1 & 1 & 0 \\
\hline Nur. techn. & 0 & 0 & 0 & 2 & 0 & 0 & 0 & 0 \\
\hline Admin. assist. & 0 & 0 & 1 & 0 & 0 & 0 & 0 & 0 \\
\hline Occup. therap & 0 & 0 & 0 & 0 & 0 & 0 & 1 & 0 \\
\hline $\begin{array}{c}\text { Total } \\
\mathrm{n} / 33=100 \%\end{array}$ & $5=15.1$ & $4=12.1$ & $6=18.2$ & $7=21.2$ & $1=3.1$ & $2=6.1$ & $5=15.1$ & $3=9.1$ \\
\hline
\end{tabular}

Caption: Recep. [Receptionist]; Soc. Worker [Social worker]; Coord. [Coordinator]; Dent. [Dentist]; Nur. [Nurse]; Phys. therap. [Physical therapist]; Phono. [Phonoaudiologist]; Doorm. [Doorman]; Nut. [Nutritionist]; Gym teach. [Gym teacher]; Pedag. [Pedagogue]; Psych. [Psychologist]; Nur. techn. [Nursing technician]; Admin. assist. [Administrative assistant]; Occup. therap. [Occupational therapist]. 
Table 2 shows that the non-verbal communication strategies adopted by the participants were: writing and gestures; lip reading and gestures; speaking slowly; mime; Libras. There was one participant who reported not knowing the Brazilian Sign Language. Similarly, one participant reported never having assisted a deaf patient; others did not answer. A total of $84.9 \%$ participants ( 28 professionals) used strategies to communicate with deaf patients other than Libras.

Deaf people have difficulties understanding the professional speech because the professional usually do not focus on the matter and speak fast or use technical terms that deaf people do not understand. Similarly, many times, the deaf cannot read what the professional wrote because of words and technical terms that the deaf does not know as the result of their deficiency in the Portuguese language or because the professional's handwriting is illegible.

Table 3 shows how participants responded when asked about what they deem more important to communicate with the deaf clientele.

Table 3. What the professionals deem as the most important to communicate with deaf patients, Três Rios/Rio de Janeiro State/RJ, 2013.

\begin{tabular}{|c|c|c|c|c|c|c|c|}
\hline Professionals & Goodwill & $\begin{array}{l}\text { Be understood/ } \\
\text { understand }\end{array}$ & $\begin{array}{c}\text { Social } \\
\text { inclusion }\end{array}$ & $\begin{array}{l}\text { Good quality } \\
\text { assistance }\end{array}$ & $\begin{array}{l}\text { Knowledge of } \\
\text { Libras }\end{array}$ & $\begin{array}{l}\text { More public } \\
\text { investments }\end{array}$ & No response \\
\hline Recep. & 0 & 1 & 1 & 1 & 0 & 0 & 0 \\
\hline S. worker & 0 & 0 & 1 & 0 & 0 & 0 & 0 \\
\hline Coord. & 0 & 1 & 0 & 0 & 0 & 0 & 0 \\
\hline Dent. & 0 & 1 & 1 & 0 & 0 & 0 & 0 \\
\hline Nur. & 0 & 1 & 0 & 0 & 0 & 0 & 0 \\
\hline Phys. therap. & 2 & 3 & 2 & 0 & 1 & 0 & 1 \\
\hline Phono. & 0 & 1 & 0 & 0 & 1 & 0 & 0 \\
\hline Doorm. & 0 & 0 & 0 & 1 & 0 & 0 & 0 \\
\hline Nut. & 0 & 0 & 1 & 0 & 0 & 0 & 1 \\
\hline Gym teach. & 0 & 0 & 1 & 0 & 1 & 0 & 0 \\
\hline Pedag. & 0 & 1 & 0 & 0 & 0 & 0 & 0 \\
\hline Psych. & 0 & 4 & 0 & 0 & 0 & 0 & 0 \\
\hline Nur. techn. & 0 & 0 & 0 & 2 & 0 & 0 & 0 \\
\hline Admin. assist. & 0 & 1 & 0 & 0 & 0 & 0 & 0 \\
\hline Occup. therap & 0 & 0 & 0 & 0 & 0 & 1 & 0 \\
\hline $\begin{array}{c}\text { Total } \\
\mathrm{n} / 33=100 \%\end{array}$ & $2=6.1$ & $14=42.3$ & $7=21.2$ & $4=12.1$ & $3=9.1$ & $1=3.1$ & $2=6.1$ \\
\hline
\end{tabular}

Caption: Recep. [Receptionist]; Soc. worker [Social worker]; Coord. [Coordinator]; Dent. [Dentist]; Nur. [Nurse]; Phys. therap. [Physical therapist]; Phono. [Phonoaudiologist]; Doorm. [Doorman]; Nut. [Nutritionist]; Gym teach. [Gym teacher]; Pedag. [Pedagogue]; Psych. [Psychologist]; Nur. techn. [Nursing technician]; Admin. assist. [Administrative assistant]; Occup. therap. [Occupational therapist].

According to participants, the most important aspects to communicating with deaf patients were: goodwill; being understood and understanding; providing good quality care; knowledge of Libras; more public funding. There were those who made allusion to social inclusion as a way to draw attention to the rights of deaf people when it comes to receiving decent care. Other participants did not express their views on the issue.

Among the 33 participants, $87.8 \%$ (29) reported not receiving any training to communicate with deaf patients during courses previously attended; $9.1 \%$ (3) stated having received a superficial training to communicate with deaf patients; and only 3.1\% (1) answered Yes, stating that communication with deaf patients was part of the curriculum in previously attended courses.

\section{Discussion}

Although $18.2 \%$ (6) of the participants informed using writing and gestures to communicate with deaf patients, 
it is noteworthy that because the deaf often do not present visual problems, writing could be an alternative. However, in reality, it is not: the oral-hearing language of the country is a second language for the deaf, and like any foreign language, the learning is difficult. Thereby, the writing is not the way to improve assistance [10].

In sign language, the word is called a signal that is formed from the combination of hand movements with a certain proper code to express certain ideas, executed in the frontal spaces of the emitting body. These hand movements, comparable to phonemes, and sometimes to morphemes, are named parameters. Thus, sign languages are structured on minimum units, which form larger and more complex units, with several linguistic levels: phonological, morphological, syntactic, semantic, and pragmatic [11] [12].

It is known that people with disabilities have the same rights as people without disabilities. However, they do not always manage to claim their rights under the same conditions as non-disabled people do because of the disadvantages imposed by their restriction in functionality and by the society, which inflicts physical, legal, and attitude barriers on them. These barriers are responsible for the gap that exists in the implementation of the rights of persons with and without disabilities [9]. This exclusion is increased with deaf people to the extent that few listeners know Libras, or are interested in learning to communicate through Libras.

Even if sign language is not known, it is essential to appropriately interpret its supra-segmental aspects that include gestures and facial and body expressions [10]. This corroborates the data presented in Table 2, in which the efforts displayed by the participants is observed; 6 reported resorting to writing and gestures, 7 relied on lipreading or speech gestures, 1 spoke slowly, and 2 used mime.

The results from a study in Canoas, Rio Grande do Sul, Brazil indicate that general and specific communication skills are needed by professionals who work in the healthcare industry, both for assistance to normal and hearing impaired patients. In many ways, the phenomena that hinder the communication between the deaf and health professionals are the same for the normal population, especially when interlocutors do not speak face to face with access to the visual field, or clearly face to face, allowing lip-reading, or using terminology out of the understanding realm for both [2].

A study conducted in a university hospital in Rio de Janeiro [5] to identify how 37 nursing professionals communicate with deaf patients revealed that none of the team members knew Libras and 21 professionals (57\%) reported never having provided care for deaf patients. The communication strategies used by $16(43 \%)$ of the professionals who had provided care for deaf patients were: 12 (46.15\%) resorted to mime; 4 (15.38\%) used lipreading; 8 (30.77\%) used writing; 1 (3.85\%) used drawing; 1 (3.85\%) used an interpreter.

Communication is indicative of quality of life, therefore when health care professionals know how to communicate properly with deaf patients they are promoting a humanized and focused assistance in the context of an inclusive society [8]. The skills to deal with people who do not share oral language and culture in the work environment are not routinely taught in schools. Thus, professionals may not be prepared to meet the needs of these patients [10].

In the context of care practices and health assistance, it is important to emphasize that communication difficulties with deaf patients are not universally accepted because some professionals try to learn effective ways to relate to these patients to provide welfare and transmit confidence. These professionals demonstrate their efforts and search for the best way to relate with this type of client, however, their success is limited due to the lack of specific preparation during academic training [13].

Health services must be planned considering the deaf patient; however, the complaints of these patients are similar to those from normal patients [14]. The improvement in the communication with the deaf clientele entails substantial improvements in terms of functional autonomy for these patients - which is the objective of physical rehabilitation programs.

It is important to note that the participants in this study belong to fifteen professional categories; all should interact properly with deaf patients to provide information about the dynamics of reception, access to programs, services, and care in the unit. Deaf patients experience exclusion and discriminatory feelings of being a foreigner in their own country in physical rehabilitation units and in any other public service unit because they cannot count on professionals to communicate through sign language [15].

It is easier for the health professional to detect what is happening with a deaf patient when he/she shows clinical signs of functional impairment or reduced mobility than when there is no apparent cause for health problems and the collection of more information is necessary for a historical composition of the patient.

It is noteworthy that the deaf can use gestures and expressions that are universally understood and do not belong to Libras -for example, expressions of pain, pointing to the pain site, and defining the type of pain. Those 
who are literate in Portuguese can also write; however, the grammatical construction is different. Therefore, the professional should patiently try to understand what the deaf patient wants to express and, otherwise, should not be afraid to ask again [2] [8].

The right of a deaf person to health and communication assumes the search from local managers to implement and materialize conditions and elements that favor the communicative process in the context of health services. This process must be carried out efficiently, respecting cultural differences, occurring through aspects of nonverbal communication and through skills to understand and decode the message transmitted by the deaf [3] [16].

In the contemporary social context in which policies and actions that promise to overcome attitudinal barriers and communication for diverse groups of individuals begin to delineate, under the guideline of respect for differences, it is necessary to question what in fact is being achieved and which changes are urgent [17]. The possibilities and ways of participation in various spheres of society constitute a crucial issue for the understanding of the reality of life in these groups [18].

Because disabilities affect a considerable portion of the world's population, the improvement in professional training in different areas of knowledge and practice is necessary, in particular in health. Trained professionals can more effectively help disabled persons and act with appropriate attitudes and skills when encountering deaf patients providing qualified assistance to their needs [19].

Out of the 33 participants in this study, $87.8 \%$ (29) reported not having received any training to communicate with deaf patients, which means significant inattention to the fact that the sign language is not considered a choice of the deaf community but its only option. According to the Federal Law No. 10436 from 24 April 2002, public institutions must enhance programs aimed at training health professionals in the care and treatment of deaf patients [3] [10] [20], which does not change much, because being a Brazilian citizen and sharing the same culture with listeners does not guarantee equal healthcare for deaf patients because the communicational barrier prevails as the result of deaf patients and professionals not sharing the same language, even if the teaching of sign language is backed by laws [8].

Various measures are adopted in the Federal, State, and Municipal instances provided by the Brazilian Constitution in order to ensure the inclusion of people with deafness in the everyday family, collective, and institutional life. For health professionals, it becomes essential to seek new paradigms to facilitate the promotion of quality and humanized health care [8]. These measures are relevant to reach contemporary social goals of harmonic coexistence with differences.

The present study also revealed that only one of the two speech therapy professionals reported receiving superficial training to communicate with deaf customers regardless of the specific mandatory legislation on inclusion of the Brazilian Sign Language discipline in the training of these professionals.

Following the example of the established standard curriculum in the United States of America in various undergraduate courses in the health area, undergraduate speech-language therapy programs in Brazil initiated since 2005 with the mandatory inclusion of Libras in their curricula [19] [20]. Although recommended as an elective course in other undergraduate health area majors, the results from this study confirm the importance of receiving training and habilitation to interact properly with deaf patients in health institutions.

This fact raises inclusive perspectives for the deaf due to compliance with the prevailing legal precept in Brazil and based on Decree No. 6949 from 25 August 2009, which promulgates the International Convention on the Rights of Persons with Disabilities and its Optional Protocol signed in New York on 30 March 2007. Noncompliance implies breaking constitutional amendment because the convention cited above was welcomed and voted in the Brazilian Parliament with a qualified quorum of three-fifths of their respective houses, in two shifts, as stipulated in the 3 rd $\S$ of art. 5 in the Federal Constitution, in just over two months, between May and June 2008; therefore, with granted equivalence to constitutional amendments [20].

The international literature also records studies about how health teams communicate with deaf patients. In that regard, we highlight studies that investigated the impact of including the teaching of sign language in professional health training in France [21], USA [22] and Netherlands [23], and about rights awareness in deaf communities in Germany [24]. These studies reveal concerns and public investments in various countries to provide assistance to the deaf community in a complete and integral manner respecting their specific codes of communication and interaction with listeners.

Lastly, the communication barriers that hinder or even prevent the interaction between deaf patients and health professionals can only be overcome when appropriate forms of interaction are established as the only way to ensure good quality assistance to these patients [7] [10] [15]. 


\section{Conclusions}

The study identified some alternative strategies adopted by professionals for the communication with deaf patients, revealing mistaken interpretations and limited understanding for the fact that the sign language is a communication resource that needs to be known and appreciated in the practice of health actions.

Among the most used communication strategies to interact with deaf patients are writing and gestures, lip reading and gestures, speaking slowly, mime and Libras - the most effective strategy used to communicate with deaf patients. Although Libras was improvised and precariously used, its use demonstrated concerns by the staff in providing conditions to serve these patients.

The study participants considered it more important to act with goodwill, making efforts to understand, respecting social inclusion rights, and providing good quality assistance. In addition, they indicated the need for more public sector investments and knowledge and mastery of Libras to ensure the same rights of accessibility to deaf patients in public regional units for physical rehabilitation.

Most of the participants reported that they had not received specific opportunities for professional training in Libras; few received basic training and some received appropriate training to communicate with deaf patients through Libras.

Finally, it is noteworthy that the communication with deaf people should be considered priority in the curricular grids of courses at all levels, because the Brazilian Sign Language is the first language for the deaf community. Without the inclusion of Libras, it is not possible to elaborate the planning of quality health services offered to all and without distinction as advocated by the Brazilian Constitution.

\section{References}

[1] Ianni, A. and Pereira, P.C.A. (2009) Acesso da comunidade surda à rede básica de saúde. Saúde e Sociedade, 18, 89-92. http://dx.doi.org/10.1590/S0104-12902009000600015

[2] Freire, D.B., Gigante, L.P., Béria, J.U., Palazzo, L.S., Figueiredo, A.C.L. and Raymann, B.C.W. (2009) Acesso de pessoas deficientes auditivas a serviços de saúde em cidade do Sul do Brasil. Cadernos de Saúde Pública, 25, 889-897. http://dx.doi.org/10.1590/S0102-311X2009000400020

[3] Bentes, I.M.S., Vidal, E.C.F. and Maia, E.R. (2011) Deaf Person's Perception on Health Care in a Midsize City: An Descriptive-Exploratory Study. Online Brazilian Journal of Nursing, 10. http://dx.doi.org/10.5935/1676-4285.20113210

[4] Machado, W.C.A., Machado, D.A., Figueiredo, N.M.A., Tonini, T., Miranda, R.S. and Oliveira, G.M.B. (2013) Sign Language: How the Nursing Staff Interacts to Take Care of Deaf Patients? Revista de Pesquisa Cuidado é Fundamental, 5, 283-292.

[5] Silva, A.B.P., Pereira, M.C.C. and Zanolli, M.L. (2007) Mães ouvintes com filhos surdos: Concepção de surdez e escolha da modalidade de linguagem. Psicologia: Teoria e Pesquisa, 23, 279-286. http://dx.doi.org/10.1590/S0102-37722007000300006

[6] Brasil Ministério da Saúde; Secretaria de Atenção à Saúde. Departamento de Ações Programáticas Estratégicas (2007) A pessoa com deficiência e o Sistema Único de Saúde. 2nd Edition, MS, Brasília.

[7] Machado, W.C.A., Figueiredo, N.M.A., Barbosa, L.A., Machado, M.C.I., Shubert, C.O. and Miranda, R.S. (2012) Política Nacional de Saúde da Pessoa com Deficiência. In: Figueiredo, N.M.A. and e Machado, W.C.A., Eds., Tratado de Cuidados de Enfermagem Médico Cirúrgico, Roca, São Paulo, 2502-2539.

[8] Nóbrega, J.D., Andrade, A.B., Pontes, R.J.S., Bosi, M.L.M. and Machado, M.M.T. (2012) Identidade surda e intervenções em saúde na perspectiva de uma comunidade usuária de língua de sinais. Ciência \& Saúde Coletiva, 17, 671679. http://dx.doi.org/10.1590/S1413-81232012000300013

[9] Brasil Presidência da República (2012) Cartilha do Censo 2010. SNPD/PR, Brasília.

[10] Chaveiro, N., Barbosa, M.A. and Porto, C.C. (2008) Revisão de literatura sobre oatendimento ao paciente surdo pelos profissionais da saúde. Revista da Escola de Enfermagem da USP, 42, 578-583. http://dx.doi.org/10.1590/S0080-62342008000300023

[11] Colin, C., Zuinen, T., Bayard, C. and Leybaert, J. (2013) Phonological Processing of Rhyme in Spoken Language and Location in Sign Language by Deaf and Hearing Participants: A Neurophysiological Study. Neurophysiologie Clinique/Clinical Neurophysiology, 43, 151-160. http://pesquisa.bvsalud.org/portal/resource/pt/mdl-23856171 http://dx.doi.org/10.1016/j.neucli.2013.03.001

[12] Bonfim, R.O. and Souza, A.P.R. (2010) Surdez, mediação e linguagem na escola. Psicologia USP, 21, 417-437.

[13] Machado, W.C.A., Figueiredo, N.M.A., Tonini, T., Silva, R.C.L. and Silca, C.R.L. (2012) The Search for a Brazilian 
Sign Language Course: A Descriptive Exploratory Study. Online Brazilian Journal of Nursing, 11, 331-345.

[14] Chaveiro, N., Duarte, S.B.R., Freitas, A.R.F., Barbosa, M.A.B., Porto, C.C. and Fleck, M.P.A. (2014) Qualidade de vida dos surdos que se comunicam pela língua de sinais: Revisão integrativa. Interface-Comunicação, Saúde, Educação, 18, 101-114. http://dx.doi.org/10.1590/1807-57622014.0510

[15] Machado, W.C.A. (2009) O surdo como estrangeiro em seu próprio país: Barreiras comunicacionais na vida cotidiana. http://saci.org.br/index.php?modulo=akemi\&parametro=33906

[16] Bittencourt, Z.Z.L.C., Françozo, M.F.C., Monteiro, C.R. and Francisco, D.D. (2011) Surdez, redes sociais e proteção social. Ciência \& Saúde Coletiva, 16, 769-776. http://dx.doi.org/10.1590/S1413-81232011000700007

[17] Lopes, M.A.C. and Leite, L.P. (2011) Concepções de surdez: A visão do surdo que se comunica em língua de sinais. Revista Brasileira de Educação Especial, 17, 305-320.

[18] Lange, C.M., Lane-Outlaw, S., Lange, W.E. and Sherwood, D.L. (2013) American Sign Language/English Bilingual Model: A Longitudinal Study of Academic Growth. Journal of Deaf Studies and Deaf Education, 18, 532-544. http://dx.doi.org/10.1093/deafed/ent027

[19] Guarinello, A.C., Berberian, A.P., Eyng, D.B., Festa, P.S.V., Marques, J.M. and Bortolozzi, K.B. (2013) A disciplina de Libras no contexto de formação acadêmica em Fonoaudiologia. Revista CEFAC, 15, 334-340. http://dx.doi.org/10.1590/S1516-18462012005000047

[20] Fonseca, R.T.M. (2012) O novo conceito constitucional de pessoa com deficiência: Um ato de coragem. In: Ferraz, C.V., Leite, G.S., Leite, G.S. and Leite, G.S., Eds., Manual dos Direitos da Pessoa com Deficiência, Saraiva, São Paulo, 19-32.

[21] Equy, V., Derore, A., Vassort, N., Mongourdin, B. and Sergent, F. (2012) Evaluation of the Actions Increasing Health Accessibility for Deaf Pregnant Patients. Journal de Gynécologie Obstétrique et Biologie de la Reproduction, 41, 561565. http://dx.doi.org/10.1016/j.jgyn.2012.04.017

[22] Cooper, S.B., Emanuel, D.C. and Cripps, J.H. (2012) Deaf Studies Alumni Perceptions of the Academic Program and Off-Campus Internship. American Annals of the Deaf, 157, 373-390.

[23] Knoors, H. and Marschark, M. (2012) Language Planning for the 21st Century: Revisiting Bilingual Language Policy for Deaf Children. Journal of Deaf Studies and Deaf Education, 17, 291-305. http://dx.doi.org/10.1093/deafed/ens018

[24] Höcker, J.T., Letzel, S. and Münster, E. (2012) Are Deaf Patients in Germany Informed about Their Legal Rights for a Sign Language Interpreter? Gesundheitswesen, 74, 818-821. 
Scientific Research Publishing (SCIRP) is one of the largest Open Access journal publishers. It is currently publishing more than 200 open access, online, peer-reviewed journals covering a wide range of academic disciplines. SCIRP serves the worldwide academic communities and contributes to the progress and application of science with its publication.

Other selected journals from SCIRP are listed as below. Submit your manuscript to us via either submit@scirp.org or Online Submission Portal.
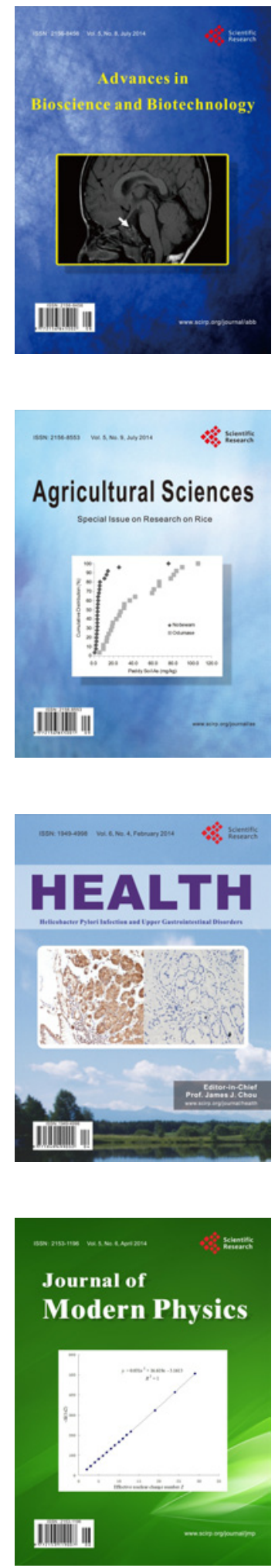
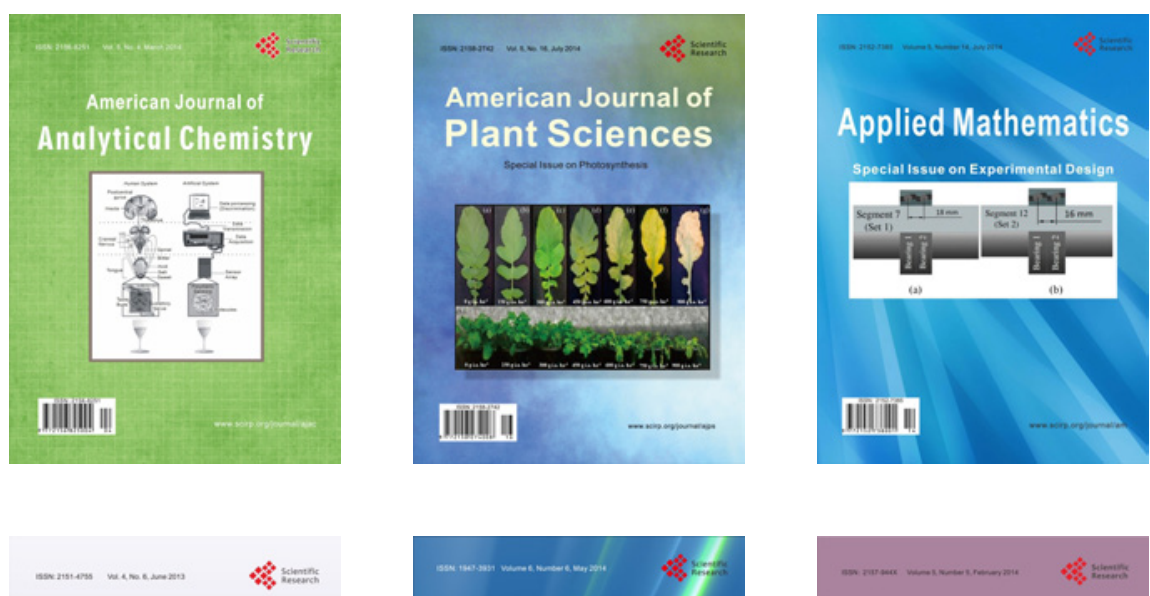

Creative Education
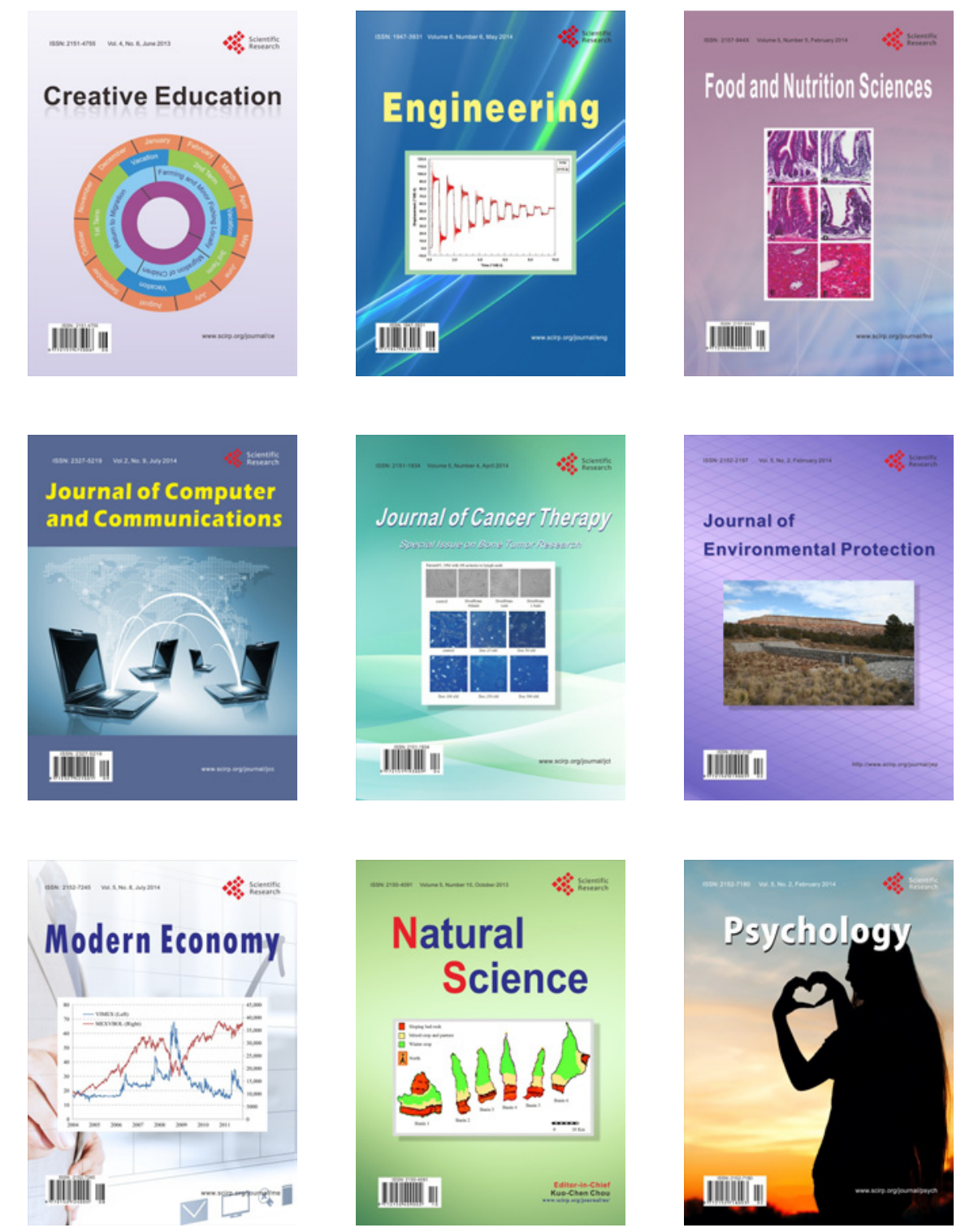